\title{
A De Novo Whole GCK Gene Deletion Not Detected by Gene Sequencing, in a Boy with Phenotypic GCK Insufficiency
}

\author{
N. H. Birkebak, ${ }^{1}$ J. S. Sørensen, ${ }^{1}$ J. Vikre-Jørgensen, ${ }^{1}$ P. K. A. Jensen, ${ }^{2}$ \\ O. Pedersen, ${ }^{3,4,5}$ and T. Hansen ${ }^{4,6,7}$ \\ ${ }^{1}$ Department of Pediatric, Aarhus University Hospital, Skejby, 8200 Aarhus C, Denmark \\ ${ }^{2}$ Department of Clinical Genetic, Aarhus University Hospital, Nørrebrogade, 8200 Aarhus C, Denmark \\ ${ }^{3}$ Hagedorn Research Institute, 2820 Gentofte, Denmark \\ ${ }^{4}$ Novo Nordisk Foundation Center for Basic Metabolic Research, Faculty of Health Sciences, University of Copenhagen, \\ 1350 Copenhagen K, Denmark \\ ${ }^{5}$ University of Aarhus, 8200 Aarhus C, Denmark \\ ${ }^{6}$ Steno Diabetes Center, 2820 Gentofte, Denmark \\ ${ }^{7}$ Faculty of Health Sciences, University of Southern Denmark, 5000 Odense C, Denmark
}

Correspondence should be addressed to N.H. Birkebæk, nielbirk@rm.dk

Received 13 July 2011; Accepted 18 August 2011

Academic Editors: A. Baumer, C.-W. Cheng, and C. Yapijakis

Copyright $\odot 2011$ N. H. Birkebæk et al. This is an open access article distributed under the Creative Commons Attribution License, which permits unrestricted use, distribution, and reproduction in any medium, provided the original work is properly cited.

\begin{abstract}
We report on a boy with diabetes mellitus and a phenotype indicating glucokinase (GCK) insufficiency, but a normal GCK gene examination applying direct gene sequencing. The boy was referred for diabetes mellitus at 7.5 years old. His father, grandfather and great grandfather suffered type $2 \mathrm{DM}$. Several blood glucose profiles showed (BG) of $6.5-10 \mathrm{mmol} / \mathrm{L}$ L. After three years on neutral insulin Hagedorn (NPH) in a dose of $0.3 \mathrm{IU} / \mathrm{kg} /$ day haemoglobin A1c (HbAlc) was 6.8\%. Treatment was changed to sulphonylurea $750 \mathrm{mg}$ a day, and after 4 years $\mathrm{HbAlc}$ was $7 \%$. At that time a multiplex ligation-dependent amplification gene dosage assay (MLPA) was done, revealing a whole GCK gene deletion. Medical treatment was ceased, and after one year HbAlc was $6.8 \%$. This case underscores the importance of a MLPA examination if the phenotype of a patient is strongly indicative of GCK insufficiency and no mutation is identified using direct sequencing.
\end{abstract}

\section{Introduction}

Monogenic diabetes results from a mutation in a single gene. Most cases are autosomal dominant inherited, but may be recessive inherited, mitochondrial inherited, or be due to a de novo mutation [1]. Monogenic diabetes should be considered when diabetes is inherited through more than two generations. A common cause of monogenic diabetes, Maturity Onset Diabetes of the Young (MODY) is mutations in the glucokinase (GCK) gene (MODY2). MODY2 is characterized by moderately elevated fasting and postprandial blood glucose levels. Treatment is usually unnecessary [1]. Until recently, mutation screening has been restricted to denaturing high-performance liquid chromatography (dHPLC) or direct sequence analyses. However these methods do not detect large heterozygous deletion mutations.

We report on a boy with diabetes mellitus and a phenotype indicating GCK insufficiency, but a normal GCK gene examination applying direct gene sequencing.

\section{Case Report}

The boy was referred for diabetes mellitus (DM) at 7.5 year old, with two fasting blood glucoses (BG) of $7-8 \mathrm{mmol} / \mathrm{L}$ and a HbAlc of $6.4 \%$. He was born at term with a birth weight of $2800 \mathrm{~g}$ and a birth length of $51 \mathrm{~cm}$. He was slightly retarded. An MRI of the brain was normal apart from an arachnoideal cyst at cisterna ambiens. The parents were nonconsanguineous. The father, grandfather, two of 


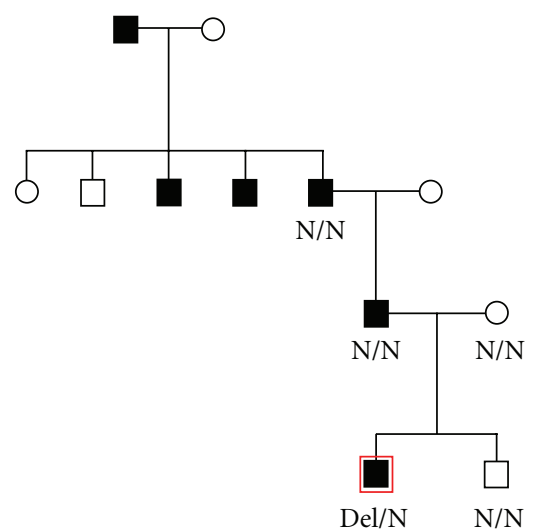

Figure 1: Pedigree of the family of the proband. The proband is marked with a red square. Filled symbols indicate family members with diabetes. The carrier of the GCK deletion mutation is marked with Del/N. Family members tested negative for the GCK deletion are marked with N/N.

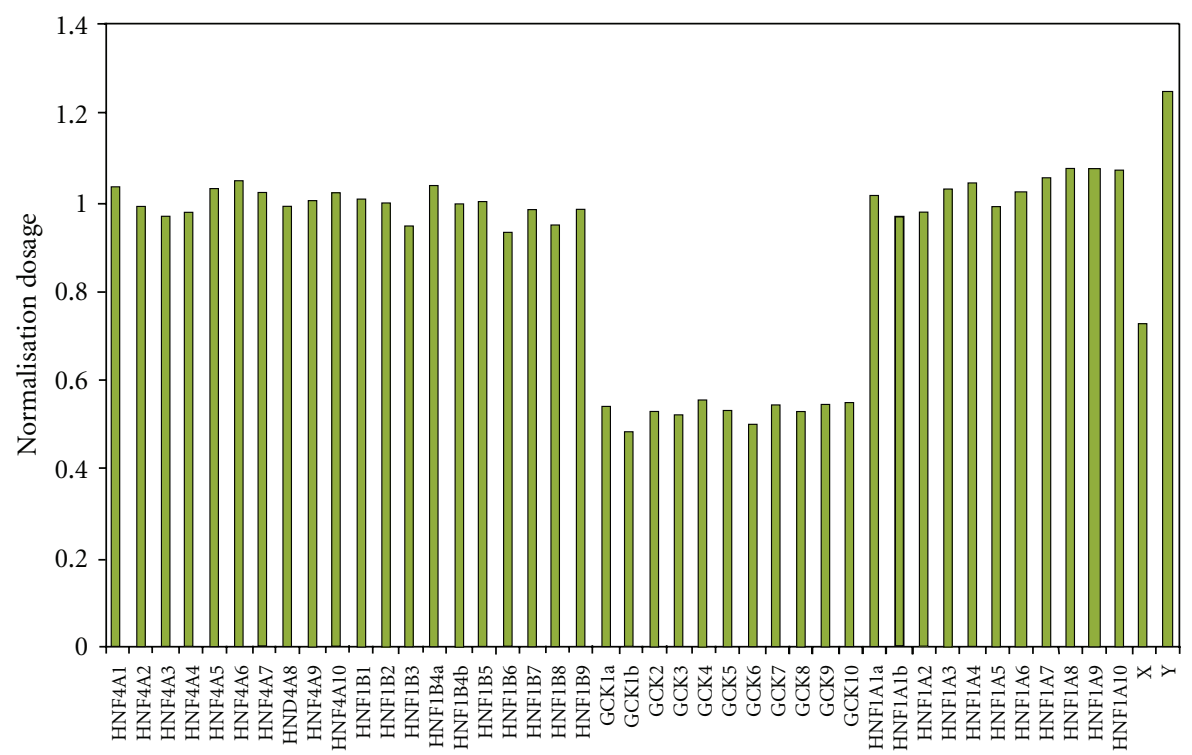

(a)

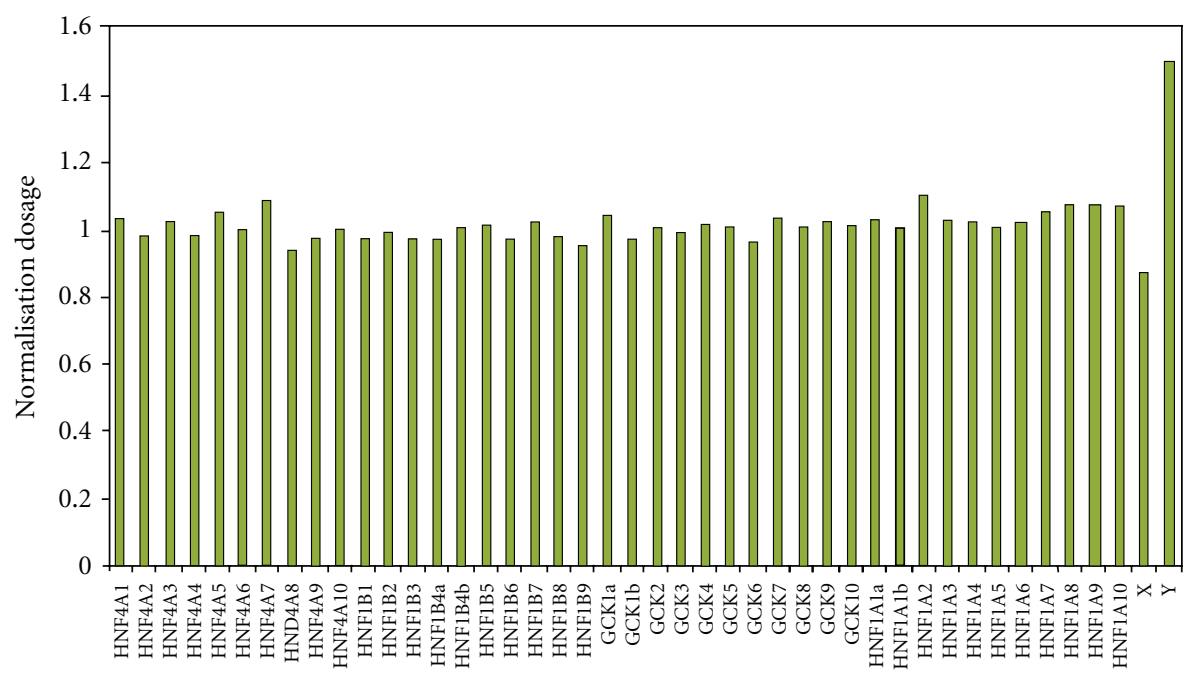

(b)

FIGURE 2: Detection of a whole GCK gene deletion (MODY2) by multiplex ligation-dependent amplification dosage assay (MLPA). Graphical representation of HNF4A (MODY1), HNF1A (MODY3), HNF1B (MODY5), GCK (MODY2), Chromosome X, and Y probes normalised to controls in the proband (a) and one of the examined family members (b). All GCK probes are expressed in half dosage in the proband indicating a total GCK deletion. 
the grandfather's brothers, and the great grandfather were diagnosed with type $2 \mathrm{DM}$ (Figure 1). The grandfather died at 54 years old. The pedigree indicated that the patient might have monogenic diabetes. However, gene sequencing of all GCK exons, intron-exon boundaries, and the promoter did not reveal any mutations. After several BG profiles of $6.5-10 \mathrm{mmol} / \mathrm{L}$, the boy was treated with $\mathrm{NPH}$ insulin $8 \mathrm{IE}$ in the morning (0.3 IE insulin per $\mathrm{kg}$ body weight). After three years on NHP $8 \mathrm{IE}$ once a day, HbAlc was $6.8 \%$. Stimulated C-peptide was $842 \mathrm{pmol} / \mathrm{L}$, and the boy was tested negative for GAD65 and IA2 autoantibodies. The treatment was changed to sulphonylurea $750 \mathrm{mg}$ a day. After four years on sulphonylurea, HbAlc was $7.0 \%$. At that time a multiplex ligation-dependent amplification dosage assay (MLPA) revealed a whole GCK gene deletion (Figure 2). The GCK gene deletion was not identified in the parents and a brother, indicating that the deletion was a de novo mutation. The sulphonylurea treatment was ceased. One year later, $\mathrm{HbAlc}$ was unchanged $6.8 \%$. An array comparative genomic hybridization of the whole genome did not reveal other mutations, and only the GCK gene was deleted.

\section{Discussion}

Most GCK mutations are single nucleotide mutations, which can be detected by dHPLC or direct gene sequencing $[2,3]$. GCK deletion mutations are very rare [4]. Until now a whole GCK deletion in nonsyndromic patients have only been reported one time [2]. In syndromic patients, whole GCK gene deletions have been reported in combination with multiple gene deletions $[5,6]$. In our patient, the pedigree and the phenotype gave a strong suspicion of a GCK mutation, and a de novo mutation with a whole GCK gene deletion was detected by MLPA. The relative low birth weight can be explained by the mother not having the GCK mutation and the fetus having the GCK mutation, which indirectly decreases fetal insulin secretion and thereby fetal growth [7]. This case emphasizes the importance of gene dosage analysis by MLPA in patients suspected for a GCK mutation, and no mutation was identified applying direct sequencing.

\section{Conflict of Interests}

N. H. Birkebæk, J. S. Sørensen, J. Vikre-Jørgensen, P. K. A. Jensen, O. Pedersen, and T. Hansen have no conflict of interests.

\section{References}

[1] A. Hattersley, J. Bruining, J. Shield, P. Njolstad, and K. C. Donaghue, "The diagnosis and management of monogenic diabetes in children and adolescents," Pediatric Diabetes, vol. 10, supplement 12, pp. 33-42, 2009.

[2] I. Garin, I. Rica, I. Estalella et al., "Haploinsufficiency at GCK gene is not a frequent event in MODY2 patients," Clinical Endocrinology, vol. 68, no. 6, pp. 873-878, 2008.

[3] S. Pruhova, P. Dusatkova, Z. Sumnik et al., "Glucokinase diabetes in 103 families from a country-based study in the
Czech Republic: geographically restricted distribution of two prevalent GCK mutations," Pediatric Diabetes, vol. 11, no. 8, pp. 529-535, 2010.

[4] S. Ellard, K. Thomas, E. L. Edghill et al., "Partial and whole gene deletion mutations of the GCK and HNF1A genes in maturityonset diabetes of the young," Diabetologia, vol. 50, no. 11, pp. 2313-2317, 2007.

[5] T. Schwarzbraun, C. Windpassinger, L. Ofner et al., "Genomic analysis of five chromosome 7p deletion patients with Greig cephalopolysyndactyly syndrome (GCPS)," European Journal of Medical Genetics, vol. 49, no. 4, pp. 338-345, 2006.

[6] S. Naik, E. Riordan-Eva, N. S. Thomas et al., "Large de novo deletion of 7 p15.1 to 7 p12.1 involving the imprinted gene GRB10 associated with a complex phenotype including features of Beckwith Wiedemann syndrome," European Journal of Medical Genetics, vol. 54, pp. 89-93, 2010.

[7] G. Velho, A. T. Hattersley, and P. Froguel, "Maternal diabetes alters birth weight in glucokinase-deficient (MODY2) kindred but has no influence on adult weight, height, insulin secretion or insulin sensitivity," Diabetologia, vol. 43, no. 8, pp. 10601063, 2000. 


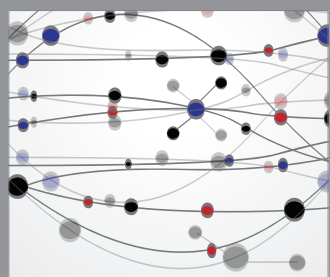

The Scientific World Journal
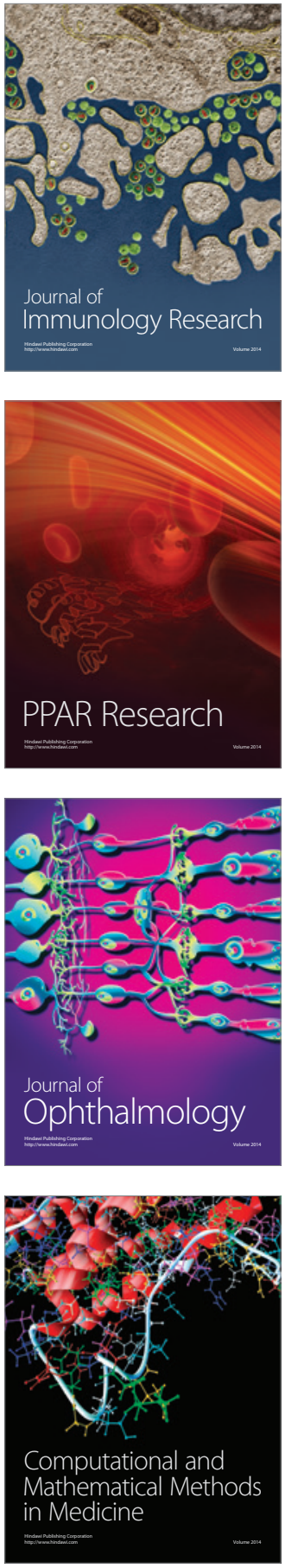

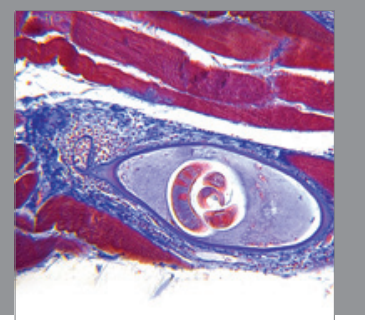

Gastroenterology

Research and Practice
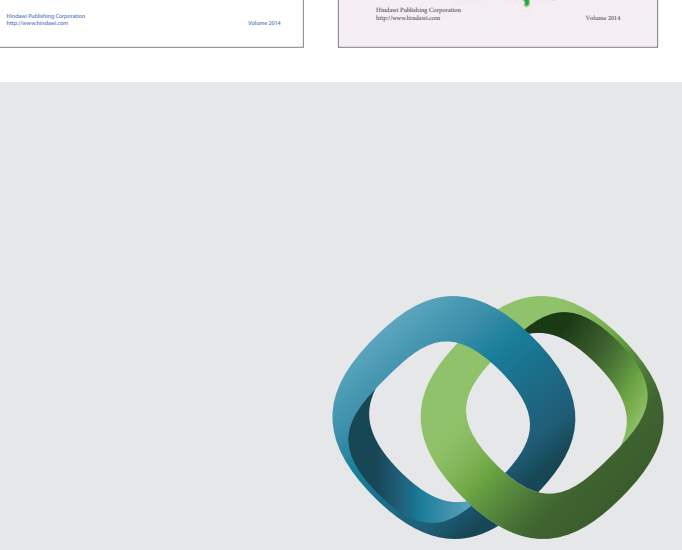

\section{Hindawi}

Submit your manuscripts at

http://www.hindawi.com
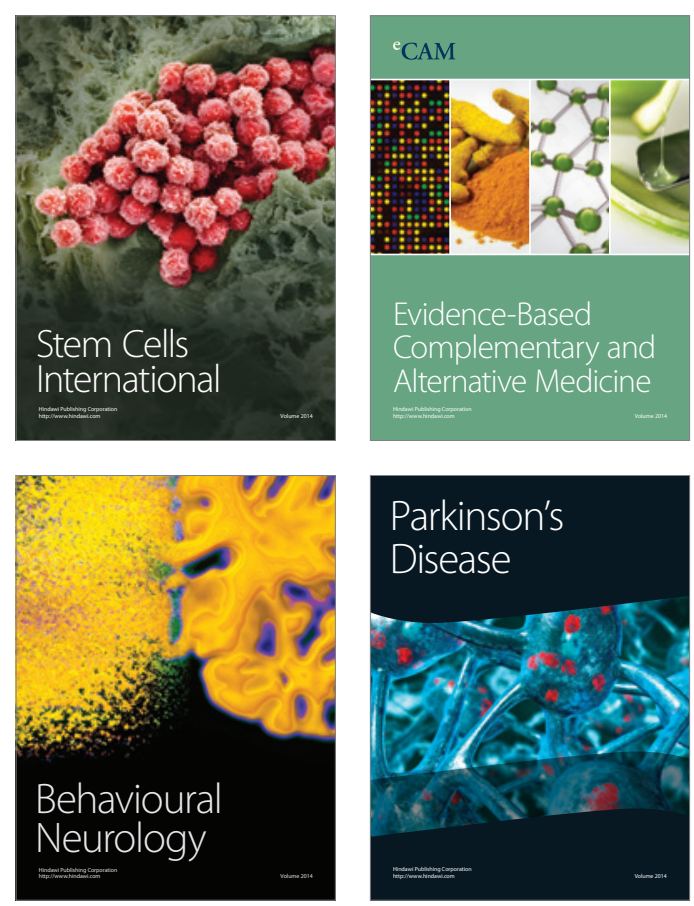

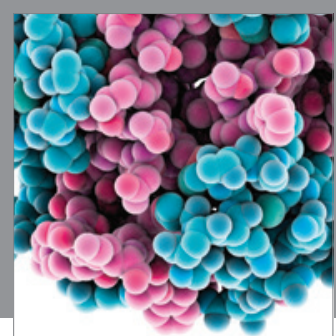

Journal of
Diabetes Research

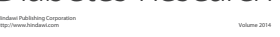

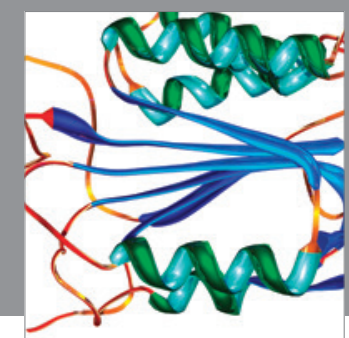

Disease Markers
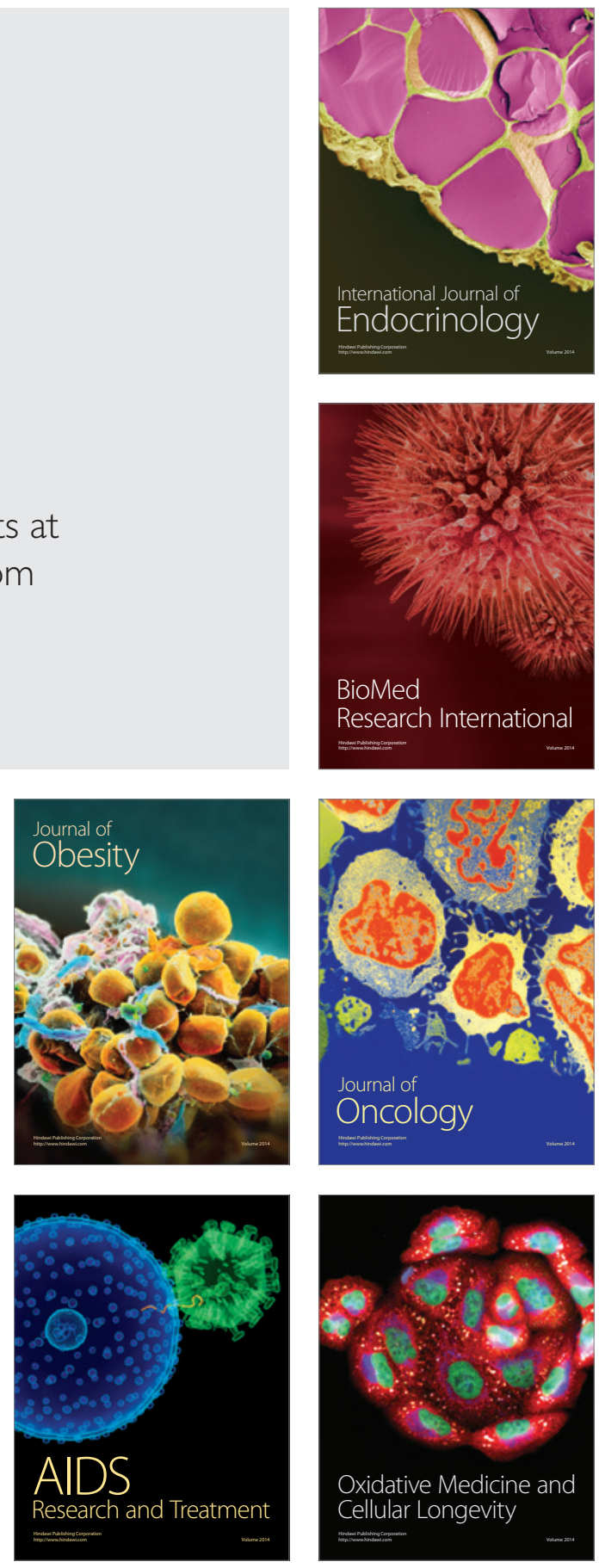